\title{
Theoretical Solutions for Dynamic Characteristics of Liquid Annular Seals with Herringbone Grooves on the Stator Based on Bulk-Flow Theory
}

\author{
Lulu Zhai $\mathbb{D}^{1},{ }^{1}$ Zhonghuang Chi, ${ }^{1}$ Jia Guo $\mathbb{D},{ }^{2}$ Zhenjie Zhang, ${ }^{1}$ and Zuchao Zhu $\mathbb{D}^{1}$ \\ ${ }^{1}$ State-Province Joint Engineering Lab of Fluid Transmission System Technology, Zhejiang Sci-Tech University, \\ 928\# No. 2 Avenue, Xiasha, Hangzhou, China \\ ${ }^{2}$ Zhejiang Institute of Mechanical \& Electrical Engineering Co., Ltd., Hangzhou, China
}

Correspondence should be addressed to Zuchao Zhu; zhuzuchao@zstu.edu.cn

Received 3 May 2018; Accepted 8 July 2018; Published 1 August 2018

Academic Editor: Alejandro Clausse

Copyright (C) 2018 Lulu Zhai et al. This is an open access article distributed under the Creative Commons Attribution License, which permits unrestricted use, distribution, and reproduction in any medium, provided the original work is properly cited.

\begin{abstract}
Liquid annular seals are primarily used to control the leakage in high-speed turbomachinery, especially in nuclear and petrochemical pumps. In this paper, a theoretical analysis method for dynamic characteristics of liquid seals with herringbone grooves on the stator is proposed based on bulk-flow theory. Steady-state velocities and leakage rates within the upstream and downstream spiral parts and the middle plain part taking account of the pumping effects are figured out first with the inertia term of the fluid within the whole seal. Then, the dynamic characteristics of the whole seal are solved based on Childs' finite-length solutions and verified by comparing with experimental hydraulic forces. Moreover, characteristic coefficients and instability parameters of the herringbone-grooved teeth-on-stator (TOS) seals and teeth-on-rotor (TOR) seals of the same size under different pressure differences are predicted and compared in detail. The influences of the lengths of constituent parts on the dynamic characteristics and instability parameters of the model seals are theoretically investigated. The results show that the stability of the TOS seal is much better than that of the TOR seal under most operating conditions. And the lengths of the middle plain part significantly affect the dynamic characteristics and the stability parameter.
\end{abstract}

\section{Introduction}

Centrifugal pumps are important equipment of nuclear power plants and petrochemical factories. In these pumps, liquid annular seals are primarily used to control the leakage. The leakage flow within the seals not only contributes to an increase of generation loss but also induces fluid forces which have significant effects on the vibration characteristics of the shafting system and the whole pump. In the present rotordynamic calculation models of centrifugal pumps, these fluid-induced forces are generally simplified as a series of rotordynamic characteristics based on a linear kinetic model. However, there are strict requirements on vibration characteristics, reliability, and safety of these nuclear and petrochemical pumps, which require annular seals facilitate superior rotordynamic characteristics while providing good leakage control. Similar to the inward pumping actions of spiral-grooved seals, liquid seals with herringbone grooves on the stator will minimize the leakage rate as well as generate load capacity and stiffness, which will contribute a lot to the improvements in hydraulic performance and pump reliability.

For decades, researchers and engineers have investigated the sealing and dynamic characteristics prediction methods for liquid annular seals based on bulk-flow model. Kostyuk [1] performed the first comprehensive analysis for the aerodynamic forces of gas labyrinth seals excluding the influence of area change due to eccentricity on cross-coupled forces. Iwatsubo [2-4] refined Kostyuk's model by introducing the time dependency of area change and theoretically analyzed the static and dynamic characteristics of parallel-grooved, spiral-grooved, and double spiral-grooved seals by perturbation method. Childs and Scharrer [5] presented a unified and comprehensive derivation of the motion equations 
for compressible flow within straight labyrinth seals taking account of the area change in circumferential direction due to eccentricity. The equations were solved by perturbation method and the prediction rotordynamic coefficients were within $25 \%$ of the experimental results. Nordmann et al. [6] and Kim [7] studied the leakage and dynamic characteristics of parallel-grooved and spiral-grooved seals by introducing equivalent roughness coefficients in both the circumferential and the axial directions based on Hirs' turbulent lubrication theory and "fine groove" theory. Florjancic [8] and Marquette [9] developed a three-control-volume approach for liquid circumferentially-grooved seals, featuring an excellent description of the flow inside the groove cavity. The predictions are excellent for leakage as well as rotordynamic coefficients. Arghir and Frene [10] proposed a bulk-flow analysis of static and dynamic characteristics of eccentric circumferentially-grooved liquid annular seals by using three types of control volumes and user-tuned constants. Zhai $[11,12]$ developed two different theoretical analysis methods for leakage rate and dynamic characteristics of herringbonegrooved liquid seals and validated the method through comparing the predicted leakage rates and hydraulic forces with the experimental results. Ikemoto [13] derived a set of perturbation solutions for the bulk-flow governing equations of annular plain seals through third-order perturbations. Through the derived equations, the nonlinear analytical solutions of the flow rates and pressure were deduced and the rotordynamic fluid forces in the case of concentric circular whirl with relatively large amplitude were solved and validated by comparisons with CFD results. Andres [14] proposed a modified bulk-flow model to predict the rotordynamic force coefficients of shallow depth, circumferentially grooved liquid seals by utilizing the results of CFD to evaluate the bulk flow velocity field and the friction factors. The CFD modified bulk-flow model predicted the rotordynamic force coefficients within $14 \%$ compared with the CFD method. Filippo [15] compared the correlations of rotordynamic characteristics with leakage formula, flow coefficient, kinetic energy carry-over coefficient, and friction factors to investigate the most accurate model for dynamic prediction. Nagai [16] introduced an oblique coordinate system to the static and dynamic analysis of a spiral-grooved seal, in which the governing equations included the effects of fluid inertia and energy loss during the passage between the groove and land parts. A series of experiments for leakage flow rates and hydraulic forces were conducted to verify the proposed method. Xia [17] developed a transient bulk flow model with arbitrary rotor motion and the boundary conditions and friction factors used in this model were calibrated with steady CFD analysis. Compared to the traditional bulk flow model, this method improved the prediction accuracy of leakage flow rates and dynamic characteristics. Zhai [18] proposed a theoretical analysis method for leakage rate and dynamic characteristics of spiral-grooved liquid seals based on the theory of Iwatsubo and Childs which has taken account of the circumferential velocity perturbation change with the axial location. Detailed comparisons between the experimental leakage rates and theoretical predictions showed good agreement and the predicted stiffness of the present solution method correlates well with the experimental evidence with an error of less than 35\% in the given examples.

Additionally, Kanki [19] and Iwatsubo et al. [20] experimentally investigated the leakage characteristics, load capacity, and dynamic characteristics for spiral-grooved seals with helical angle less than 20 degrees. Childs and Nolan [21, 22] tested the leakage rate and dynamic characteristics of 7 sets of spiral-grooved seals whose helical angle varied from 0 to 70 degrees. Proctor and Delgado [23] tested a noncontacting finger seal operating adjacent to a herringbone-grooved rotor under various operating conditions. Winoto et al. [24] tested 6 types of vertical HGJBs at rotating speeds ranging from 200 to $2100 \mathrm{r} / \mathrm{min}$ and studied the effects of groove patterns on the pumping sealing effect and the stiffness of the bearings. Qiu [25] conducted a series of experiments to investigate the tribological behavior of spiral-groove thrust bearings with different spiral angles subjected to different loads and speeds.

Recently, with the development of Computational Fluid Dynamics (CFD), CFD method has been giving more accurate prediction results of sealing and dynamic characteristics of annular seal with complex grooves, but the method are not computationally efficient. Therefore, theoretical prediction procedures based on the bulk-flow theory are still the main method for calculating leakage rate and dynamic characteristics in engineering. Extensive theoretical analysis for leakage flow rates and dynamic characteristics of liquid annular seals with complex grooves is still needed. Consequently, in this paper, systematic solution method for leakage and dynamic characteristics of liquid seals with herringbone grooves on the stator is proposed based on a modified solution for spiral-grooved seals, which has added the pressure difference induced by pumping actions of spiral grooves into Childs' model [7]. In this method, steady-state velocities and pressures as well as leakage rates of the two spiral parts and middle plain part are solved first with the inertia term of the fluid based on the mass conservation law. Then, the dynamic characteristics of seals with herringbone grooves are derived combined with finite-length solution developed by Childs. With the proposed method, the rotordynamic forces within three different model seals are calculated and compared to the experimental results. Moreover, the effects of pressure differences, preswirl ratios and groove patterns on the dynamic characteristics and stability of the seals with herringbone grooves on the stator are investigated using this method.

\section{Theoretical Analysis}

2.1. Modelling. Since annular seals with grooves on the stator will provide better stability, this kind of seal is more widely used in turbomachinery. In this paper, a smoothrotor/herringbone-grooved-stator seal (as shown in Figure 1) is selected as the research model and the spiral angle of the model is less than 15 degrees. The radial clearance between the rotor and the stator, combined with large pressure difference and low viscosity liquid, makes the flow in the clearance path highly turbulent. Figure 2 shows the hydraulic model of a 


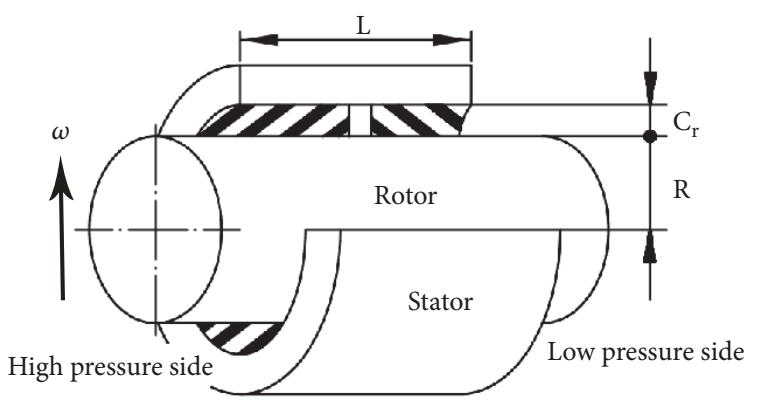

Figure 1: Schematic of a liquid annular seal with herringbone grooves on the stator.

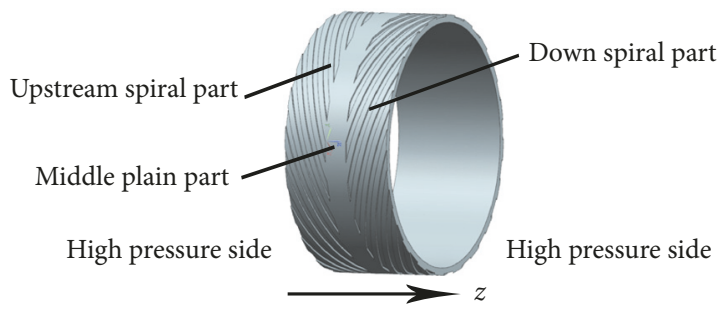

Figure 2: Hydraulic model of a smooth-rotor/herringbonegrooved-stator seal.

liquid annular seal with herringbone grooves on the stator. It is observed that the model is composed of three parts: flow within the two spiral parts and flow within the middle plain part. In the present analysis, fluid velocities and pressures within the seals are assumed to be uniformly distributed along the circumferential direction.

\subsection{Leakage Flow Rates of Herringbone-Grooved Liquid Seals}

2.2.1. Steady Flow Velocities and Leakage Flow Rates of Spiral Parts. Referring to the analysis method shown in [11], a $\eta$ $z-\zeta$ coordinate system is built to analyze the static characteristics of the spiral part. $\eta$-Direction and $\zeta$-direction are, respectively, set parallel and perpendicular to the groove direction. Figure 3(a) illustrates a differential element of fluid having dimensions $\operatorname{Rd} \theta, \mathrm{dz}$, and $\mathrm{H}(\mathrm{z}, \theta, \mathrm{t})$ within the spiral part. And Figure 3(b) illustrates the detailed cross-sectional view of the spiral part along the $\zeta$-direction. The upper and lower surface of the element, respectively, correspond to the rotor and the stator surfaces, which have velocities of $R \omega$ and zero. Under the assumptions of "fine groove" theory, the governing equations including continuity equation and axial and circumferential momentum equations based on Blasuis lubrication model are built by Childs [7]. Eccentricity ratio $\varepsilon$ is introduced as the perturbation term to linearize the governing equations. The zeroth-order perturbation equations describe a steady, zero-eccentricity flow condition and are listed below.
Nondimensional zeroth-order perturbation axial-momentum equation for the spiral part is

$$
\begin{aligned}
-\frac{\partial \bar{p}_{0-\text { sp }}}{\partial z}= & a_{1} \sigma_{r \eta-\text { sp }} \\
& +a_{2} \sigma_{s \zeta-\text { sp }} \cos \alpha\left(\cos \alpha+\frac{1}{b} \bar{u}_{\theta 0-\text { sp }} \sin \alpha\right) \\
& +a_{3} \sigma_{s \eta-\text { sp }} \sin \alpha\left(\sin \alpha-\frac{1}{b} \bar{u}_{\theta 0-\text { sp }} \cos \alpha\right)
\end{aligned}
$$

Nondimensional zeroth-order perturbation circumferential-momentum equation for the spiral part is

$$
\begin{aligned}
-\frac{\partial \bar{u}_{\theta 0-s \mathrm{p}}}{\partial z}= & a_{4} \sigma_{r \zeta-\mathrm{sp}}\left(\bar{u}_{\theta 0-\mathrm{sp}}-1\right) \\
& +a_{2} b \sigma_{s \zeta-\mathrm{sp}} \sin \alpha\left(\cos \alpha+\frac{1}{b} \bar{u}_{\theta 0-\mathrm{sp}} \sin \alpha\right) \\
& -a_{3} b \sigma_{s \eta-\mathrm{sp}} \cos \alpha\left(\sin \alpha-\frac{1}{b} \bar{u}_{\theta 0-\mathrm{sp}} \cos \alpha\right)
\end{aligned}
$$

where

$$
\begin{aligned}
& a_{1}=\frac{1}{2}\left[\frac{1+\left(1 / b^{2}\right)\left(\bar{u}_{\theta 0-s p}-1\right)^{2}}{1+1 / 4 b^{2}}\right]^{\left(1+m_{r \eta-s p}\right) / 2} \\
& \sigma_{r \eta-\mathrm{sp}}=\frac{L_{\mathrm{sp}}}{C_{r}} n_{r \eta-\mathrm{sp}} R_{e z 0}^{m_{r \eta-\mathrm{sp}}}\left(1+\frac{1}{4 b^{2}}\right)^{\left(1+m_{r \eta-\mathrm{sp}}\right) / 2} \text {, } \\
& a_{2}=\frac{1}{2}\left[\frac{\left(1+\left(1 / b^{2}\right) \bar{u}_{\theta 0-s p}^{2}\right)}{\left(1+1 / 4 b^{2}\right)}\right]^{\left(1+m_{s \zeta-s p}\right) / 2}, \\
& \sigma_{s \zeta-\mathrm{sp}}=\frac{L_{\mathrm{sp}}}{C_{r}} n_{s \zeta-\mathrm{sp}} R_{e z 0}^{m_{s \zeta-\mathrm{sp}}}\left(1+\frac{1}{4 b^{2}}\right)^{\left(1+m_{s \zeta-\mathrm{sp}}\right) / 2} \text {, } \\
& a_{3}=\frac{1}{2}\left[\frac{\left(1+\left(1 / b^{2}\right) \bar{u}_{\theta 0-\mathrm{sp}}^{2}\right)}{\left(1+1 / 4 b^{2}\right)}\right]^{\left(1+m_{s \eta-s \mathrm{sp}}\right) / 2} \text {, } \\
& \sigma_{s \eta-\mathrm{sp}}=\frac{L_{\mathrm{sp}}}{C_{r}} n_{s \eta-\mathrm{sp}} R_{e z 0}^{m_{s \eta-\mathrm{sp}}}\left(1+\frac{1}{4 b^{2}}\right)^{\left(1+m_{s \eta-\mathrm{sp}}\right) / 2} \text {, } \\
& a_{4}=\frac{1}{2}\left[\frac{\left(1+\left(1 / b^{2}\right) \bar{u}_{\theta 0-s p}^{2}\right)}{\left(1+1 / 4 b^{2}\right)}\right]^{\left(1+m_{r \zeta-s p}\right) / 2}, \\
& \sigma_{r \zeta-\mathrm{sp}}=\frac{L_{\mathrm{sp}}}{C_{r}} n_{r \zeta-\mathrm{sp}} R_{e z 0}^{m_{r \zeta} \zeta \mathrm{sp}}\left(1+\frac{1}{4 b^{2}}\right)^{\left(1+m_{r \zeta \zeta \mathrm{sp}}\right) / 2} \text {, } \\
& b=\frac{V_{\mathrm{sp}}}{(R \omega)}, \\
& R_{e z 0}=\frac{2 \rho V_{\mathrm{sp}} C_{r}}{\mu}, \\
& m_{r \eta-s p}=-0.25 \text {, }
\end{aligned}
$$




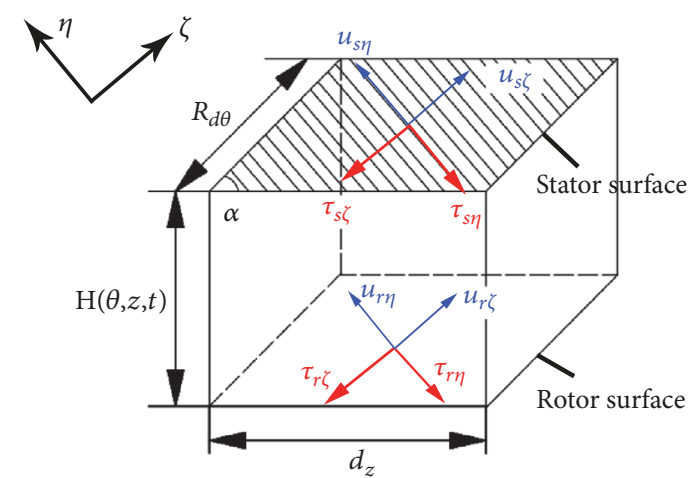

(a) Fluid differential element within the spiral part

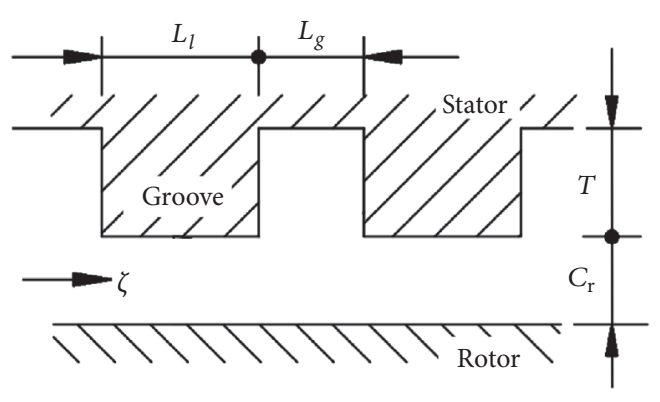

(b) Cross-sectional view of the spiral part

FIgURE 3: Configurations of the spiral part.

$$
\begin{aligned}
& n_{r \eta-\mathrm{sp}}=0.079, \\
& m_{s \zeta-\mathrm{sp}}=-0.072, \\
& n_{s \zeta-\mathrm{sp}}=0.8285, \\
& m_{s \eta-\mathrm{sp}}=-0.25, \\
& n_{s \eta-\mathrm{sp}}=0.079 \\
& m_{r \zeta-\mathrm{sp}}=-0.25 \\
& n_{r \zeta-\mathrm{sp}}=0.079
\end{aligned}
$$

Effective pressure difference across the spiral part is the result of operating pressure and the pumping effects induced by spiral grooves. The pressure difference generated by pumping effects is described based on the experimental results of Vohr and Chow [26]. The equivalent pressure difference due to the pumping action is listed below:

$$
\begin{aligned}
& \Delta p_{\text {pumping }} \\
& =0.0159 R_{e \theta 0}{ }^{0.778} \cdot \frac{6 \mu R \omega L_{\mathrm{sp}}}{C_{r}{ }^{2}} \\
& \quad \cdot \frac{L_{l g}\left(1-L_{l g}\right)\left(K_{e}^{3}-1\right)\left(K_{e}-1\right) \tan \alpha}{K_{e}{ }^{3}\left(1+\tan ^{2} \alpha\right)+L_{l g}\left(1-L_{l g}\right)\left(K_{e}{ }^{3}-1\right)^{2} \tan ^{2} \alpha}
\end{aligned}
$$

where $R_{e \theta 0}=2 R \omega \rho \bar{u}_{\theta 0-\mathrm{sp}} C_{r} / \mu, L_{\mathrm{lg}}=L_{l} /\left(L_{l}+L_{g}\right)$, and $K_{e}=$ $T /\left(T+C_{r}\right)$.

The nondimensional zeroth-order perturbation governing (1) and (2) is coupled and nonlinear through the dependency of the variable $\mathrm{V}_{\mathrm{sp}}$. Thus, the equations and variable $V_{\mathrm{sp}}$ can be solved iteratively with the specified pressure drop $\Delta p$ and the boundary conditions for $\bar{u}_{\theta 0-s p}$ listed as (5). Note that, for the upstream spiral part, the effective pressure difference is less than the initial one shown as (6). However, the situation is just the reverse for the downstream spiral part shown as (7).

$$
\bar{u}_{\theta 0-\mathrm{sp}}(0)=\frac{u_{\theta i n l e t}}{R \omega}
$$

For upstream spiral part

$$
\begin{aligned}
\Delta p_{\text {up }}-\Delta p_{\text {up-pumping }}= & \frac{1}{2}\left(1+\xi_{\text {in-sp }}\right) \rho V_{u p}{ }^{2} \\
& -\frac{1}{2}\left(1-\xi_{\text {out }-\mathrm{sp}}\right) \rho V_{u p}^{2} \\
& +\lambda_{s p} \rho V_{u p}^{2}
\end{aligned}
$$

For downstream spiral part

$$
\begin{aligned}
& \Delta p_{\text {down }}+\Delta p_{\text {down-pumping }} \\
& =\frac{1}{2}\left(1+\xi_{\text {in-sp }}\right) \rho V_{\text {down }}{ }^{2}-\frac{1}{2}\left(1-\xi_{\text {out }-\mathrm{sp}}\right) \rho V_{\text {down }}{ }^{2} \\
& \quad+\lambda_{\text {sp }} \rho V_{\text {down }}^{2}
\end{aligned}
$$

where the inlet loss coefficient $\xi_{\text {in-sp }}$ and outlet recovery coefficient $\xi_{\text {out-sp }}$ is determined referring to Iwatsubo's theoretical approach for spiral-grooved seals in [3]. The friction factor $\lambda_{\mathrm{sp}}$ is determined by Hirs' turbulent lubrication equations developed in 1974 [27].

Therefore, the total leakage flow rates $Q_{\text {up }}$ and $Q_{\text {down }}$, respectively, for the upstream spiral and downstream spiral part are illustrated as below:

$$
\begin{gathered}
Q_{\text {up }}=2 \pi R^{2} C_{r} \omega \bar{V}_{u p} \\
Q_{\text {down }}=2 \pi R^{2} C_{r} \omega \bar{V}_{\text {down }}
\end{gathered}
$$

2.2.2. Steady Flow Velocities and Leakage Flow Rate of the Whole Seal with Herringbone Grooves on the Stator. The pressure drop across the plain part consists of three parts, i.e., the inlet loss, outlet loss, and friction pressure loss. As the friction factor $\lambda_{\text {plain }}$ which is derived from Hirs' equation is one-order magnitude greater than the inlet and outlet loss coefficients for a typical seal, the leakage rate of the plain part excluding the inlet and outlet pressure losses can be simplified as

$$
Q_{\text {plain }}=2 \pi R \sqrt{\frac{\Delta P_{\text {plain }} \cdot C_{r}{ }^{3}}{\lambda_{\text {plain }} L_{\text {plain }} \rho}}
$$




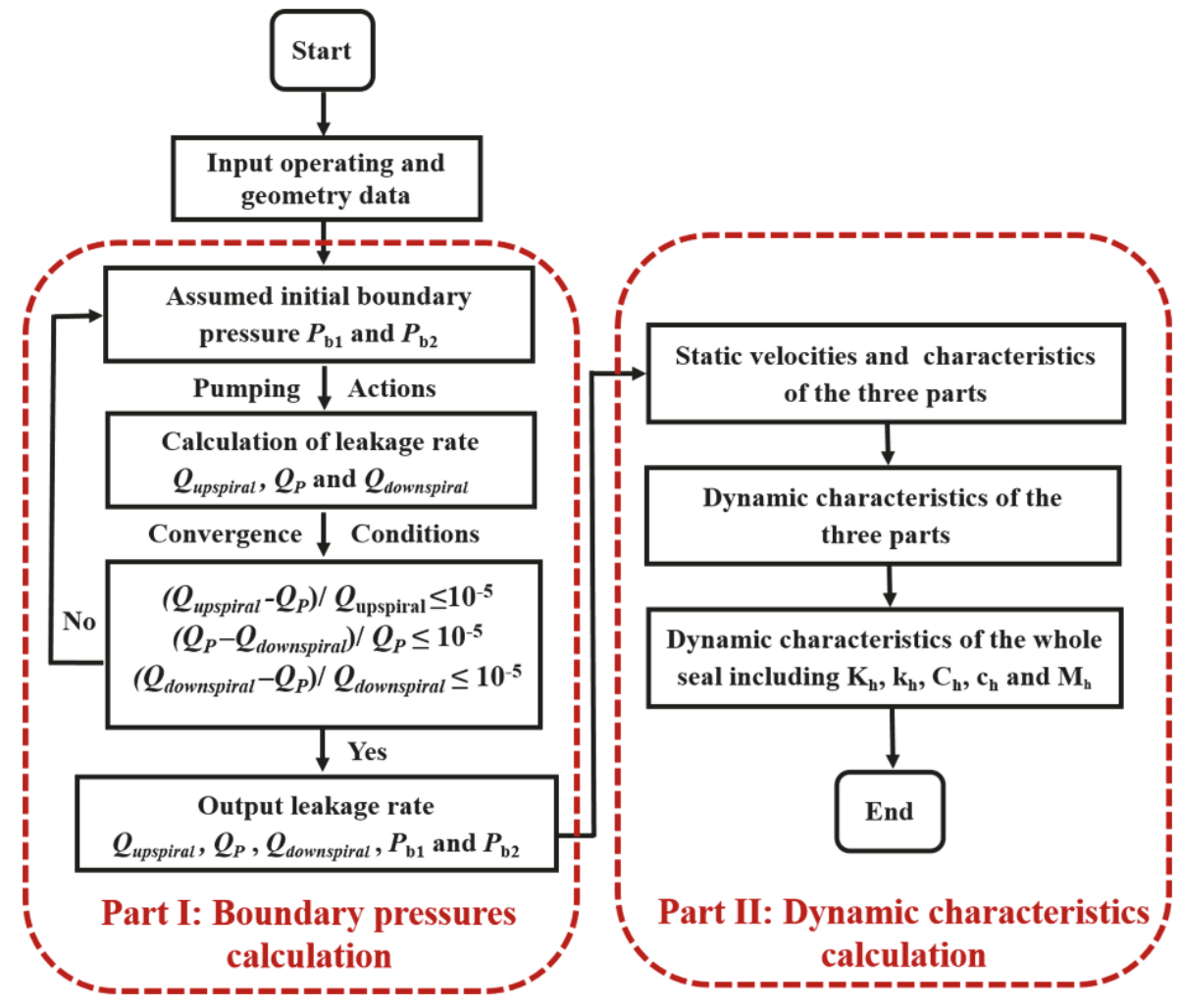

FIgURE 4: Procedure chart of the rotordynamic characteristics calculation.

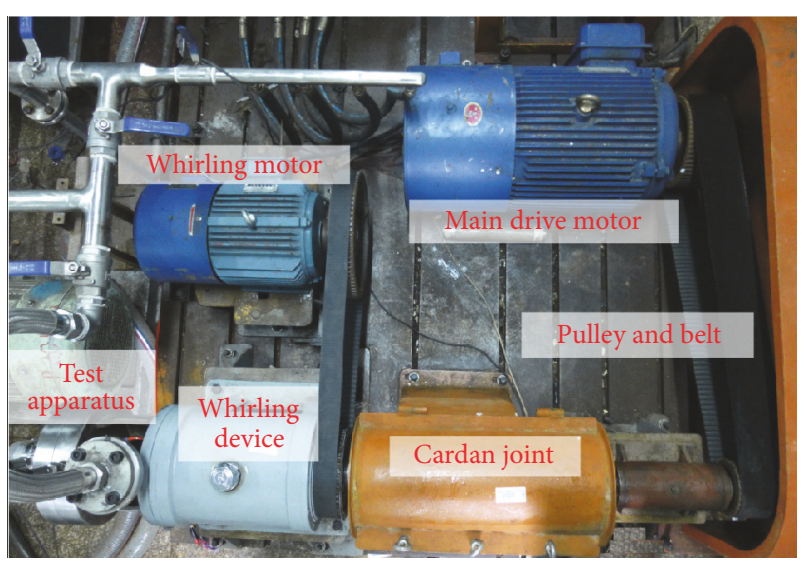

Figure 5: Global graph of the test rig.

The leakage flow rates of the upstream spiral part, downstream spiral part, and the middle plain part should be the same for a particular annular seal with herringbone grooves on the stator under certain operating conditions due to the mass conservation. Furthermore, the velocity distributions at the outlet of each part are used as the inlet flow conditions of the next part and will definitely affect the leakage rate and dynamic characteristics of the next part.

As described in (8), (9), and (10), the leakage flow rate of each part depends on the pressure gradient acting on itself. Hence, the inlet and outlet pressures of the middle plain part

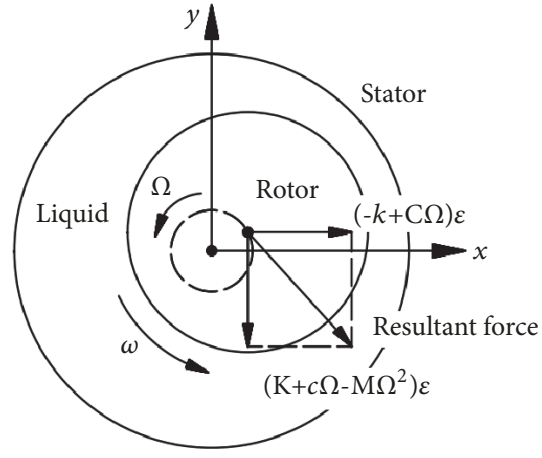

FIgURE 6: Whirling and rotating motions of a tested rotor and the forces on it.

can be regarded as two boundary pressures $P_{\mathrm{b} 1}$ and $P_{\mathrm{b} 2}$. Thus these two boundary pressures can be obtained by solving the conservation equation of the three parts shown as (13) using traversing method. The static characteristics including leakage flow rate and steady-flow velocities of the whole seal will be figured out with the solved boundary pressures.

$$
Q_{\text {up }}\left(P_{\text {in }}, P_{b 1}\right)=Q_{\text {plain }}\left(P_{b 2}, P_{b 1}\right)=Q_{\text {down }}\left(P_{b 2}, P_{\text {out }}\right)
$$

2.3. Dynamic Characteristics of Liquid Annular Seals with Herringbone Grooves on the Stator. As is shown in Figure 4, the total procedure mainly includes two parts: boundary pressures calculation and dynamic characteristics prediction. 


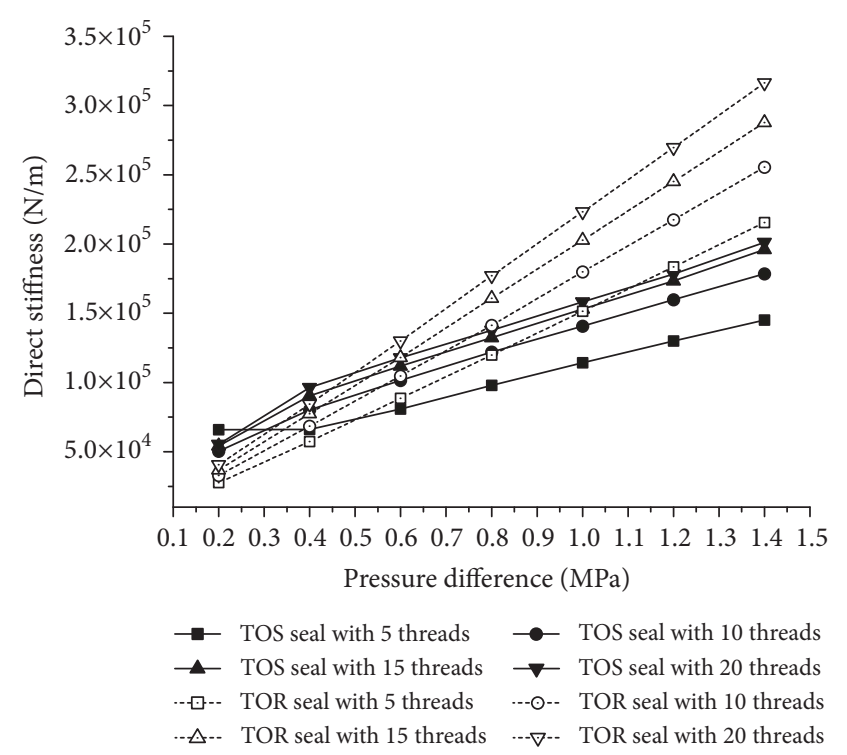

(a) Direct stiffness versus pressure difference

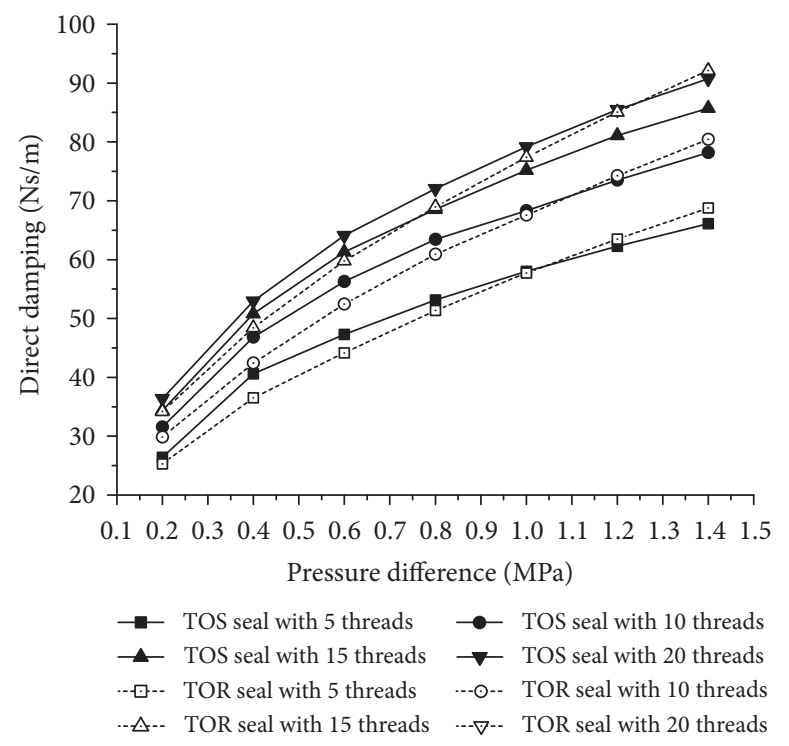

(c) Direct damping versus pressure difference

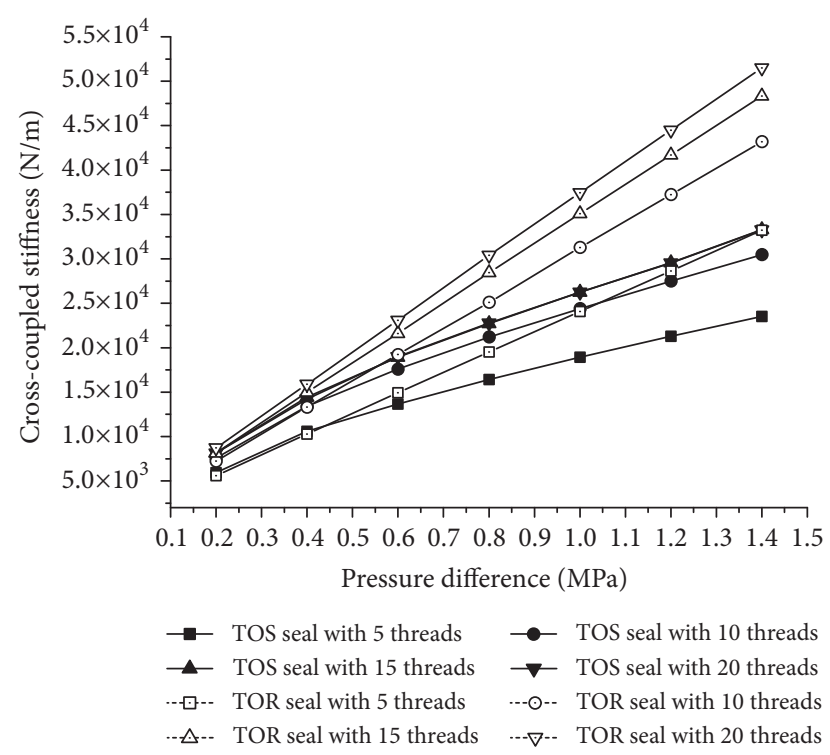

(b) Cross-coupled stiffness versus pressure difference

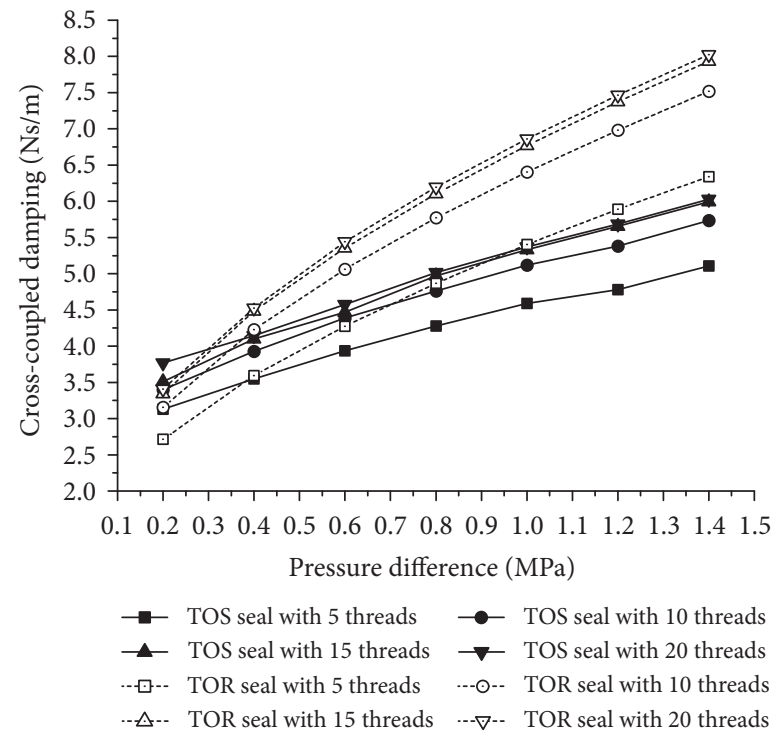

(d) Cross-coupled damping versus pressure difference

FIGURE 7: Comparisons between dynamic characteristics of herringbone-grooved TOR and TOS seals.

TABLE 1: Configurations of the model seals.

\begin{tabular}{lcccc}
\hline Seal & $\begin{array}{c}\text { Length of upstream } \\
\text { spiral part }(\mathrm{mm})\end{array}$ & $\begin{array}{c}\text { Length of middle } \\
\text { plain part }(\mathrm{mm})\end{array}$ & $\begin{array}{c}\text { Length of } \\
\text { downstream spiral } \\
\text { part }(\mathrm{mm})\end{array}$ & $\begin{array}{c}\text { Total length } \\
(\mathrm{mm})\end{array}$ \\
\hline 1 & 4 & 4 & 4 & 12 \\
2 & 8 & 4 & 8 & 20 \\
5 & 12 & 4 & 12 & 28 \\
\hline
\end{tabular}

In the first part, steady-state velocities and leakage rates of the two spiral parts and the middle plain part are solved first using the assumed initial boundary pressures. Then, an axial leakage equilibrium among the three parts is employed as the convergence condition in the cycle of boundary pressures calculation. In the second part, solutions for dynamic forces and characteristics of liquid annular seals with spiral grooves on the stator developed by Kim [7] are applied to solve those of the upstream and downstream spiral parts. And the finitelength solutions proposed by Childs [28] are used for solving 
TABLE 2: Operating conditions and geometric parameters of the tested HGLSs.

\begin{tabular}{lccc}
\hline Journal diameter $(\mathrm{mm})$ & 67 & Fluid density $\left(\mathrm{kg} / \mathrm{m}^{3}\right)$ & 1000 \\
Radial clearance $(\mathrm{mm})$ & 0.5 & Dynamic viscosity $(\mathrm{mPa} \cdot \mathrm{s})$ & 1.009 \\
Groove depth $(\mathrm{mm})$ & 0.5 & Whirling speed $(\mathrm{r} / \mathrm{min})$ & 1440 \\
Groove width $(\mathrm{mm})$ & 1.5 & Pressure difference $(\mathrm{kPa})$ & 142 \\
Land width $(\mathrm{mm})$ & 1.5 & Rotating speed $(\mathrm{r} / \mathrm{min})$ & $360-2160$ \\
Spiral angle $\left({ }^{\circ}\right)$ & 3.97 & Number of thread & 5 \\
\hline
\end{tabular}

those of the middle plain part. Thus, dynamic forces and characteristics of the whole seal with herringbone grooves on the stator are obtained by integrating those of the three parts together.

2.4. Validation of the Solution Method. Experiments for three sets of model seals with herringbone grooves on the stator were conducted on a specially designed test rig shown in Figure 5 and the details of the test rig were described in [11]. During the test, a forced whirling motion with a speed of $\Omega$, as shown in Figure 6, was applied on the rotor despite of its own rotation. The measured hydraulic forces $F_{\mathrm{h}}$ are postprocessed using FFT filter to exclude the other forces such as centrifugal force and gravity. Therefore, the validity of the presented approach is demonstrated by comparing the measured resultant forces and the predicted ones which can be figured out using (12). The three model seals have the same diameters, clearances, spiral angles, land and groove depths, and widths but different lengths of each part (i.e., upstream spiral part, middle plain part and downstream spiral part) as listed in Table 1. Table 2 demonstrates the operating conditions and the identical geometric parameters of the seals.

$$
F_{h}=\varepsilon \sqrt{\left(K_{h}+c_{h} \Omega-M_{h} \Omega^{2}\right)^{2}+\left(-k_{h}+C_{h} \Omega\right)^{2}}
$$

Table 3 shows the predicted and measured resultant forces of the three model seals under a series of rotating speeds. It is illustrated that the variations of the predicted and experimental results are accordant. The prediction results have a maximum error of $18.52 \%$. This discrepancy is partly due to the influence of convective inertial effect which is one of the predominant factors causing groove-land discontinuities and is neglected in the steady-flow characteristics analysis in (4). Most importantly, the bulk flow theory uses a series of empirical friction factors to describe the fluid governing equations without analyzing the velocity and pressure distribution details within the groove part and the land part. In general, the predicted results correlate well with the experimental evidence within allowable range of error in engineering, which verifies the proposed calculation method and the analysis below based on it.

\section{Results and Discussions}

Figure 7 shows the effects of pressure difference on the dynamic characteristics of herringbone-grooved teeth-onstator (TOS) and teeth-on-rotor (TOR) seals. From the diagram, it can be seen that both the direct stiffness and the

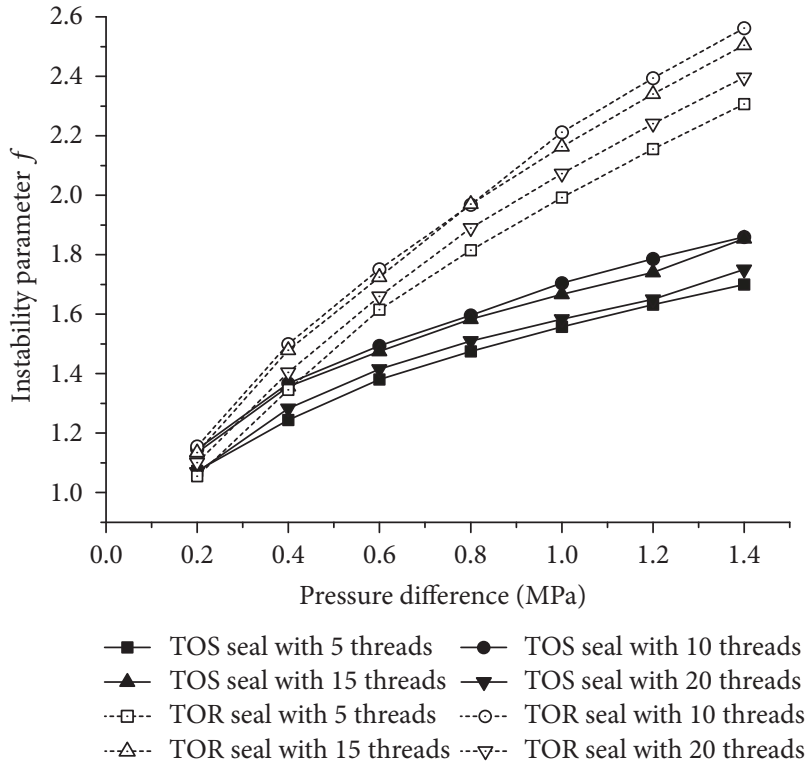

FIGURE 8: Instability parameter $f$ of herringbone-grooved TOR and TOS seals under different pressure differences.

cross-coupled stiffness of the four TOS seals increase linearly with pressure difference. The main damping and crosscoupled damping show a parabolic growth with the increase of pressure difference. Under the same working conditions, the main stiffness, cross-coupled stiffness, and cross-coupled damping coefficients of the TOS seals are smaller than those of TOR seals with the same geometry. And the variations of the three dynamic coefficients for TOS seals are much smaller than those of the TOR seals. Meanwhile, the direct damping coefficients of both types with the same number of heads have basically consistent variations with the pressure difference.

Among the four dynamic characteristic coefficients, the coefficient $k$ acts to drive a rotor in a forward whirl motion, while the coefficient $\mathrm{C}$ acts to strengthen the backward whirl which will contribute a lot to the stability of the shafting system. From a stability viewpoint, engineers and researchers would like to reduce the cross-coupled stiffness coefficient $k$ and increase the damping coefficient $C$. Thus, a nondimensional instability parameter $f$ shown in (13) is defined as a ratio to describe the strength comparisons between destabilizing and stabilizing tangential forces.

$$
f=\frac{k}{(\omega C)}
$$




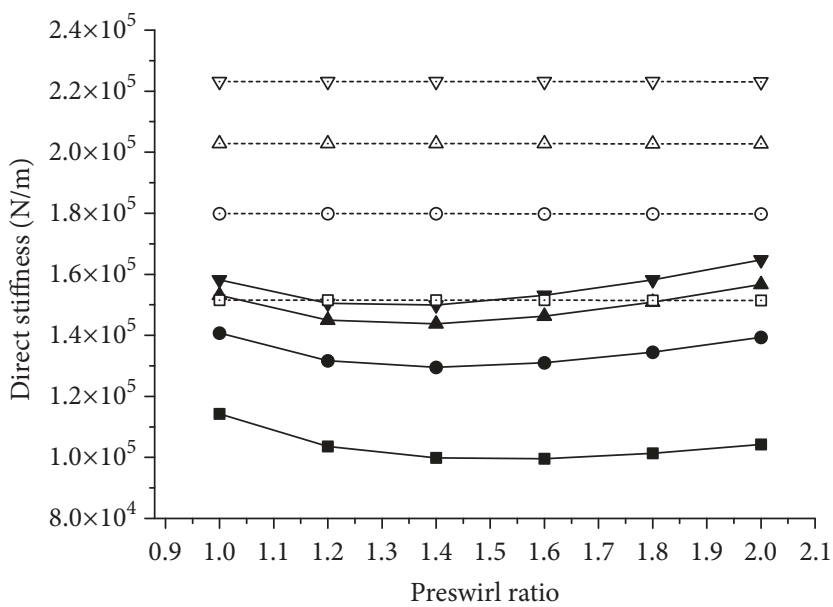

$\rightarrow$ TOS seal with 5 threads $\longrightarrow$ TOS seal with 10 threads

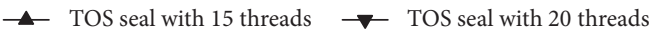

..๑-- TOR seal with 5 threads $\quad$..-๑-- TOR seal with 10 threads

-.-- TOR seal with 15 threads $\quad \cdots-\nabla--\quad$ TOR seal with 20 threads

(a) Direct stiffness versus preswirl ratio

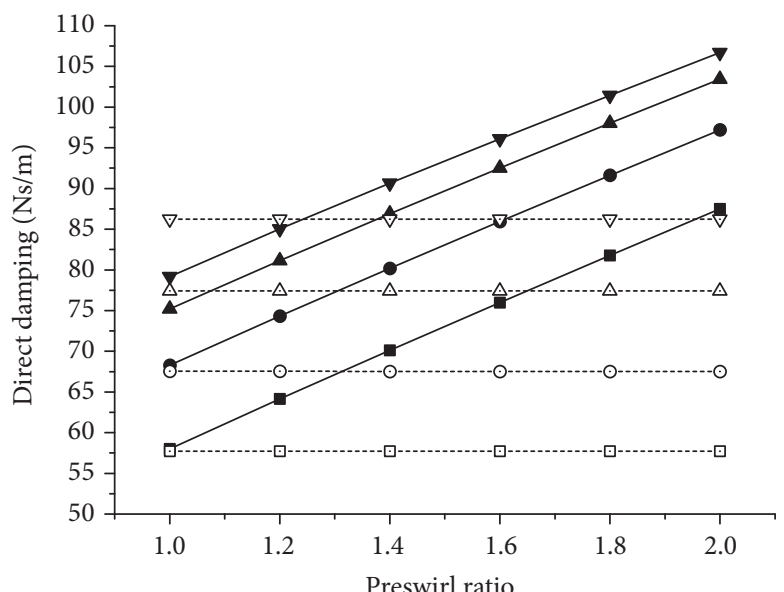

$\rightarrow$ TOS seal with 5 threads $\longrightarrow$ TOS seal with 10 threads

- TOS seal with 15 threads $\boldsymbol{\nabla}$ TOS seal with 20 threads

.-.-. TOR seal with 5 threads $\quad$..-๑-- TOR seal with 10 threads

$-\triangle-$ TOR seal with 15 threads $\quad-\nabla^{--}$TOR seal with 20 threads

(c) Direct damping versus preswirl ratio

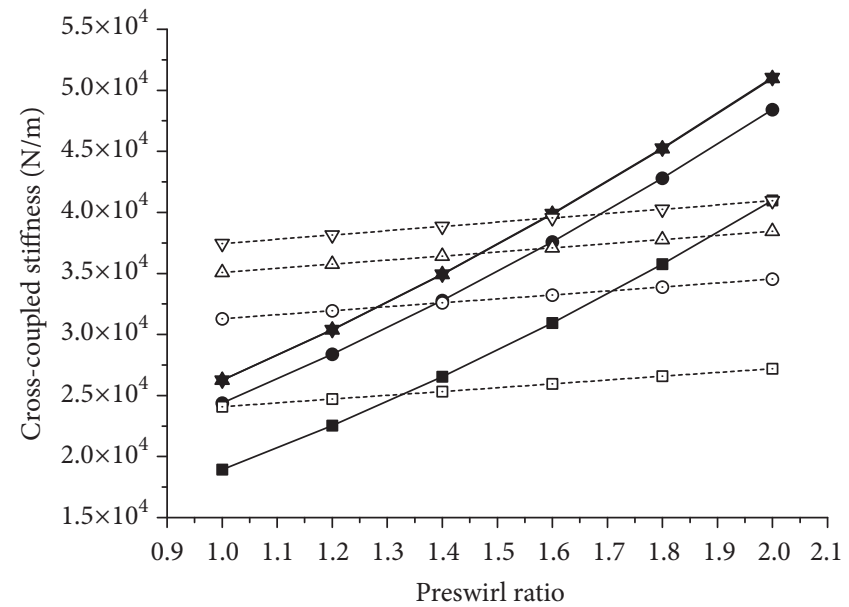

$\rightarrow$ TOS seal with 5 threads $\longrightarrow$ TOS seal with 10 threads

$\smile$ TOS seal with 15 threads $\underset{\boldsymbol{}}{ }$ TOS seal with 20 threads

..--- TOR seal with 5 threads $\quad$..-๑-- TOR seal with 10 threads

..--. TOR seal with 15 threads $\quad \cdots-\nabla--\quad$ TOR seal with 20 threads

(b) Cross-coupled stiffness versus preswirl ratio

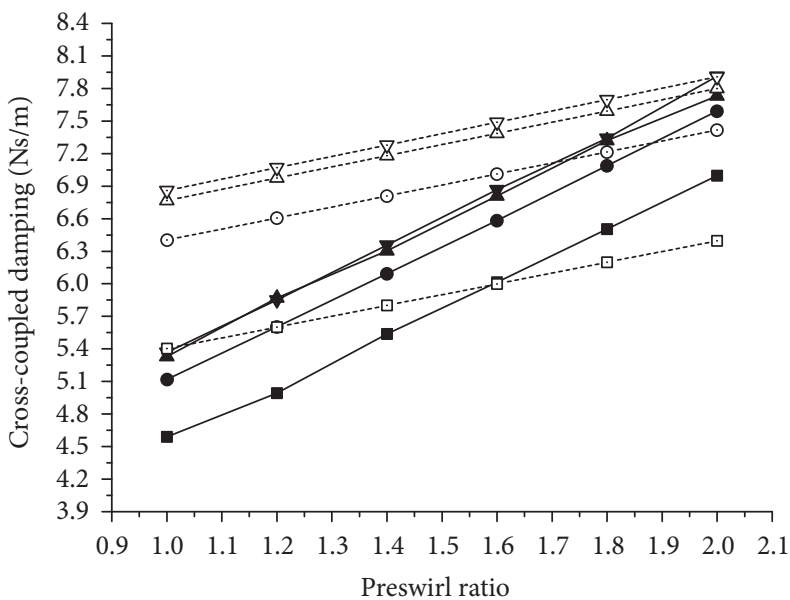

- TOS seal with 5 threads $\longrightarrow$ TOS seal with 10 threads

- - TOS seal with 15 threads $\rightarrow$ TOS seal with 20 threads

-.--- TOR seal with 5 threads $\quad$-.-๑-- TOR seal with 10 threads

$\triangle-$ - TOR seal with 15 threads $\quad-\nabla^{--}$TOR seal with 20 threads

(d) Cross-coupled damping versus preswirl ratio

FIGURE 9: Dynamic characteristic changes of herringbone-grooved TOR and TOS seals with preswirl ratio.

TABLE 3: Comparisons between predicted and measured resultant forces.

\begin{tabular}{|c|c|c|c|c|c|c|c|}
\hline & & \multicolumn{6}{|c|}{ Rotating speed (r/min) } \\
\hline & & 720 & 1080 & 1440 & 1800 & 2160 & 2400 \\
\hline \multirow{3}{*}{ Seal 1} & Predicted force $(\mathrm{N})$ & 0.3595 & 0.4290 & 0.4965 & 0.6122 & 0.8042 & 1.0006 \\
\hline & Measured force $(\mathrm{N})$ & 0.38 & 0.46 & 0.54 & 0.69 & 0.96 & 1.19 \\
\hline & Error (\%) & 5.4010 & 6.7447 & 8.0536 & 11.2803 & 16.2262 & 15.9123 \\
\hline \multirow{3}{*}{ Seal 2} & Predicted force $(\mathrm{N})$ & 0.9133 & 0.9252 & 0.9378 & 0.9568 & 0.9745 & 1.0000 \\
\hline & Measured force $(\mathrm{N})$ & 0.88 & 0.92 & 0.94 & 0.97 & 1.04 & 1.08 \\
\hline & Error (\%) & 3.7852 & 0.5598 & 0.2362 & 1.4144 & 5.9183 & 7.4046 \\
\hline \multirow{3}{*}{ Seal 3} & Predicted force $(\mathrm{N})$ & 0.3677 & 0.4362 & 0.4978 & 0.6011 & 0.7651 & 0.9370 \\
\hline & Measured force $(\mathrm{N})$ & 0.34 & 0.41 & 0.51 & 0.65 & 0.89 & 1.15 \\
\hline & Error (\%) & 8.1564 & 6.3828 & 2.3838 & 7.5167 & 14.0353 & 18.5189 \\
\hline
\end{tabular}




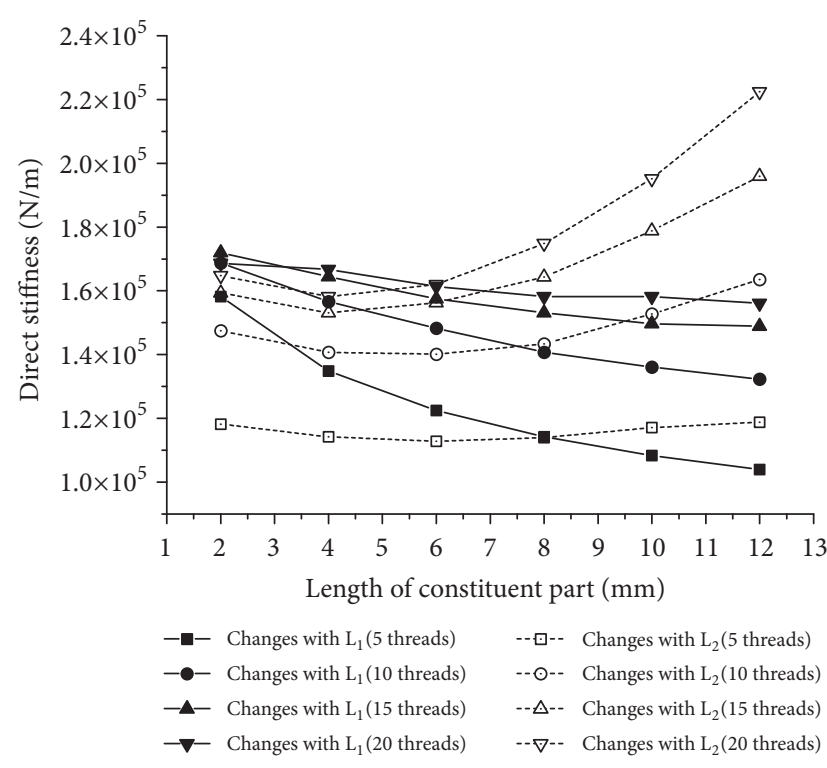

(a) Direct stiffness versus $L_{1}$ and $L_{2}$

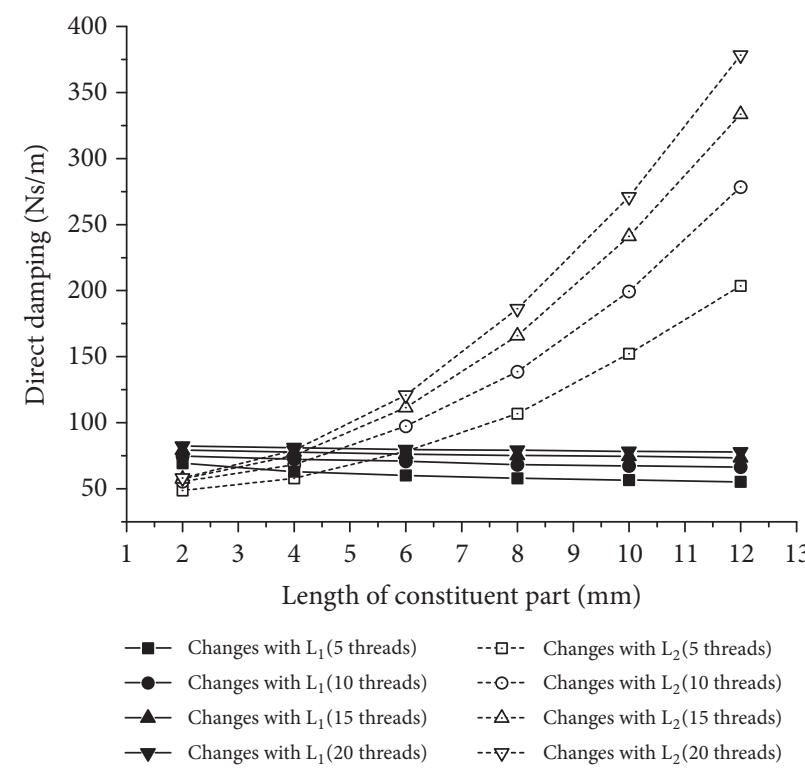

(c) Direct damping versus $\mathrm{L}_{1}$ and $\mathrm{L}_{2}$

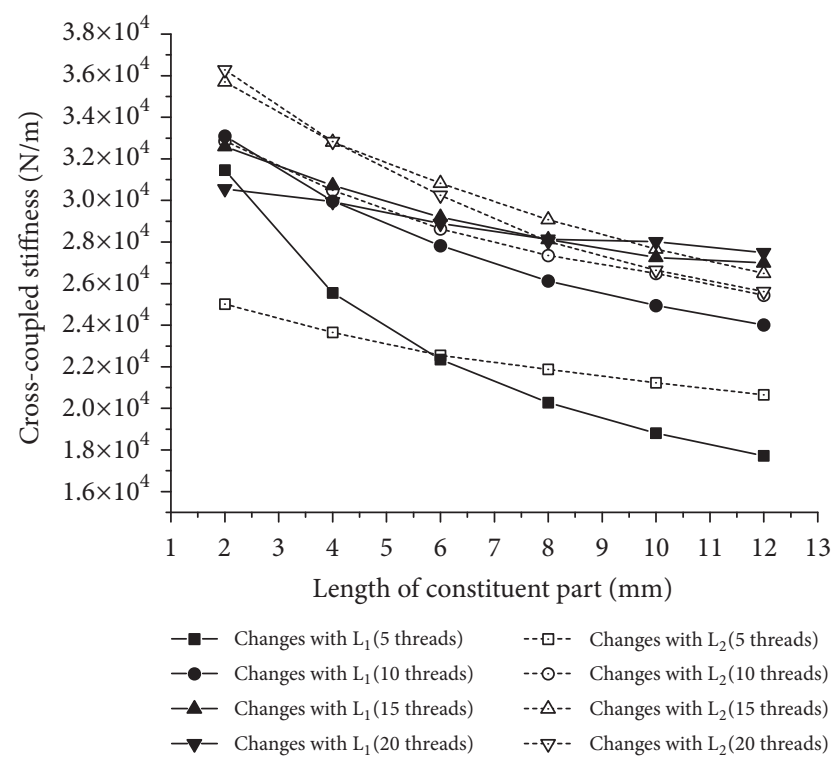

(b) Cross-coupled stiffness versus $\mathrm{L}_{1}$ and $\mathrm{L}_{2}$

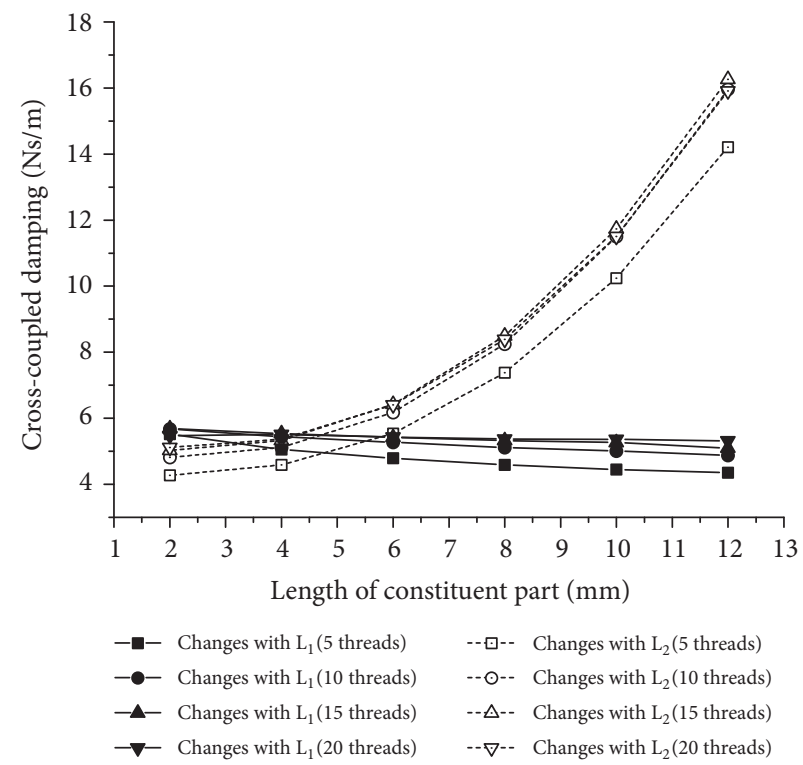

(d) Cross-coupled damping versus $\mathrm{L}_{1}$ and $\mathrm{L}_{2}$

FIgURE 10: Dynamic characteristic changes versus $\mathrm{L}_{1}$ and $\mathrm{L}_{2}$.

Plots of the parameter $f$ of TOS seals and TOR seals of the same size are provided in Figure 8. As is shown, under most operating conditions, the stability of the TOS seal is significantly better than that of the TOR seal. Moreover, as the pressure difference increases, the instability parameter of the TOR seal rises sharply while the TOS seal changes slowly, which means that TOS seal has more advantages. In the given example, the instability parameters of the 8 sets of seals are all around 1.4 under the pressure difference of $0.4 \mathrm{MPa}$. However, when the pressure difference gradually increases to $1.4 \mathrm{MPa}$, the instability parameter of TOR seal is nearly $40 \%$ higher than the TOS seal. This advantage of herringbone-grooved TOS seal is consistent with other
TOS seals with complex grooves, such as straight labyrinth seal, hole-pattern seal, honeycomb seal, and other damping seals. Thus, in the design of herringbone-grooved seals, seal stability, stiffness, and sealing performances should be considered comprehensively to meet the design requirements of the shafting system.

Dynamic characteristic coefficients are sensitive to circumferential variables, especially the inlet circumferential velocity and Reynolds number. Thus, a preswirl ratio $\gamma$ is defined as $\gamma=2 u_{\theta 0} / R \omega$ to describe the preswirl strength at the seal inlet. Figures 9(a)-9(d) compare the dynamic characteristics changes of TOR seal and TOS seal with preswirl ratio. As is shown, the dynamic coefficients of TOS 


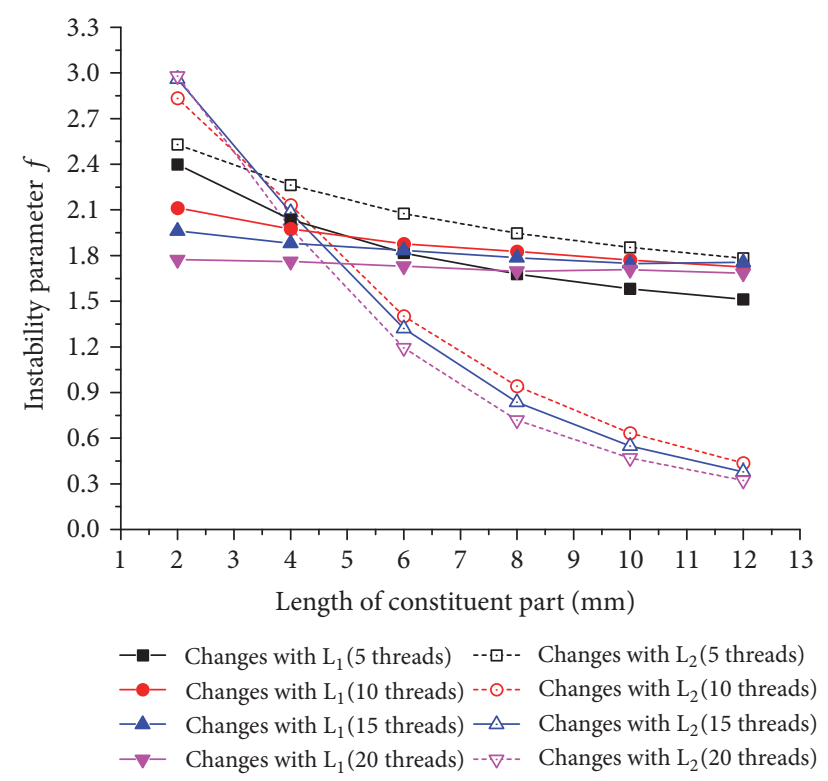

FIGURE 11: Instability parameter $f$ changes versus $\mathrm{L}_{1}$ and $\mathrm{L}_{2}$.

seal are much more sensitive than those of TOR seals, especially cross-coupled stiffness, direct damping, and crosscoupled damping. The direct stiffness of TOS seal decreases first and then increases with the increasing preswirl ratio, while the stiffness of TOR seals shows little change. The crosscoupled stiffness and direct damping of TOS seals show linear increases with preswirl ratio.

Figure 10 illustrates the coefficients changes versus the length of upstream spiral part $L_{1}$, the length of middle plain part $\mathrm{L}_{2}$. It is noted that the length of downstream spiral part $\mathrm{L}_{3}$ is equal to $\mathrm{L}_{1}$ in the given examples of this paper. A univariable analysis method is performed and a herringbonegrooved TOS seal with a structure of $8 \mathrm{~mm}-4 \mathrm{~mm}-8 \mathrm{~mm}$ is set as the reference model. That is to say, when $\mathrm{L}_{1}$ is chosen to be the variable, $\mathrm{L}_{2}$ is always $4 \mathrm{~mm}$, while $\mathrm{L}_{1}$ is $8 \mathrm{~mm}$ when $\mathrm{L}_{2}$ is chosen to be the research object. It is shown that $\mathrm{L}_{2}$ has greater influence on the dynamic characteristics coefficients compared with $\mathrm{L}_{1}$, especially on the two damping coefficients. Direct-stiffness decreases with an increase in $L_{1}$ while it increases significantly with $\mathrm{L}_{2}$. Cross-coupled stiffness shows that parabolic decreases with the increase in $\mathrm{L}_{1}$ and $\mathrm{L}_{2}$. Direct damping and cross-coupled damping coefficients show little change with $\mathrm{L}_{1}$. Moreover, the stiffness coefficients of seals with 5 threads are more sensitive to the change of seal length.

The effects of $\mathrm{L}_{1}$ and $\mathrm{L}_{2}$ on the instability parameter $f$ are investigated in detail and the results are shown in Figure 11. It is shown that the parameters of seals with 10 threads, 15 threads, and 20 threads decrease slightly with increasing $\mathrm{L}_{1}$ but sharply with $\mathrm{L}_{2}$. However, $\mathrm{L}_{1}$ and $\mathrm{L}_{2}$ almost have the same influence on the instability parameter of the seals with 5 threads.

Through the comparisons listed in Figures 10 and 11, it can be found that both the length of middle plain part $\mathrm{L}_{2}$ and the length of the whole seal $L$ have great influence on the dynamic characteristics of the model seals. Thus, the nondimensional coefficient $\mathrm{L}_{2} / \mathrm{L}$ is used to describe the influence of middle plain part on the dynamic characteristics. Figures 12(a)-12(d) present the characteristic coefficients changes versus $\mathrm{L}_{2} / \mathrm{L}$ ratio under the total length of $10 \mathrm{~mm}, 20 \mathrm{~mm}$, and $30 \mathrm{~mm}$, respectively. It is indicated that the ratio has greater influence on the dynamic characteristics of longer seals. Among the four coefficients, cross-coupled damping is the least sensitive one to spiral angle. Direct stiffness and cross-coupled stiffness coefficients of the four $10 \mathrm{~mm}$-length seals with different spiral angles decrease linearly with $\mathrm{L}_{2} / \mathrm{L}$ ratio, while the coefficients of the $20 \mathrm{~mm}$-length and $30 \mathrm{~mm}$-length seals increase significantly with the ratio. Moreover, $\mathrm{L}_{2} / \mathrm{L}$ ratio has great influence on all the four dynamic characteristic coefficients, especially when $\mathrm{L}_{2} / \mathrm{L}$ ratio is greater than 0.3 .

\section{Conclusions}

A theoretical analysis method for dynamic characteristics of liquid annular seals with herringbone grooves on the stator is proposed based on the studies of Childs and Kim. And the accuracy of the analytical method is verified by comparing with the experimental results. With the proposed analysis method, characteristic coefficients and instability parameters of the TOS seals and TOR seals of the same size under different pressure differences are predicted and compared. The comparisons show that, from a stability viewpoint, herringbone-grooved TOS seal is significantly better than TOR seal under most operating conditions. Besides, the dynamic coefficients of TOS seals are much more sensitive to the preswirl ratio than the coefficients of TOR seals, especially the cross-coupled stiffness, direct damping, and cross-coupled damping.

Additionally, the influence of the lengths of constituent parts on the dynamic characteristics and instability parameters of the model seals are theoretically investigated. It is observed that the nondimensional coefficients $\mathrm{L}_{2} / \mathrm{L}$ have great influence on all the four rotordynamic characteristics, especially when the ratio is greater than 0.3 . Therefore, it is possible to optimize the constitutions and detailed parameters of liquid annular seals with herringbone grooves on the stator for better sealing and rotordynamic performance.

\section{Nomenclatures}

\section{Roman Letters}

$C_{r}: \quad$ Mean radial clearance of the whole seal

$C, c: \quad$ Direct and cross-coupled damping coefficients

$\mathrm{H}(z, \theta, \mathrm{t})$ : Clearance function, illustrated in Figure 3(a)

$K, k: \quad$ Direct and cross-coupled stiffness coefficients

$L: \quad$ Length of the whole seal

$L_{l}: \quad \quad$ Land width of the spiral part in $\zeta$ - direction

$L_{\mathrm{g}}: \quad$ Groove width of the spiral part in $\zeta$ - direction

$m, n$ : Nondimensional empirical turbulence coefficients

$P, \Delta P: \quad$ Pressure difference

$P_{\mathrm{b} 1}: \quad$ Boundary pressure at the inlet of middle plain part 


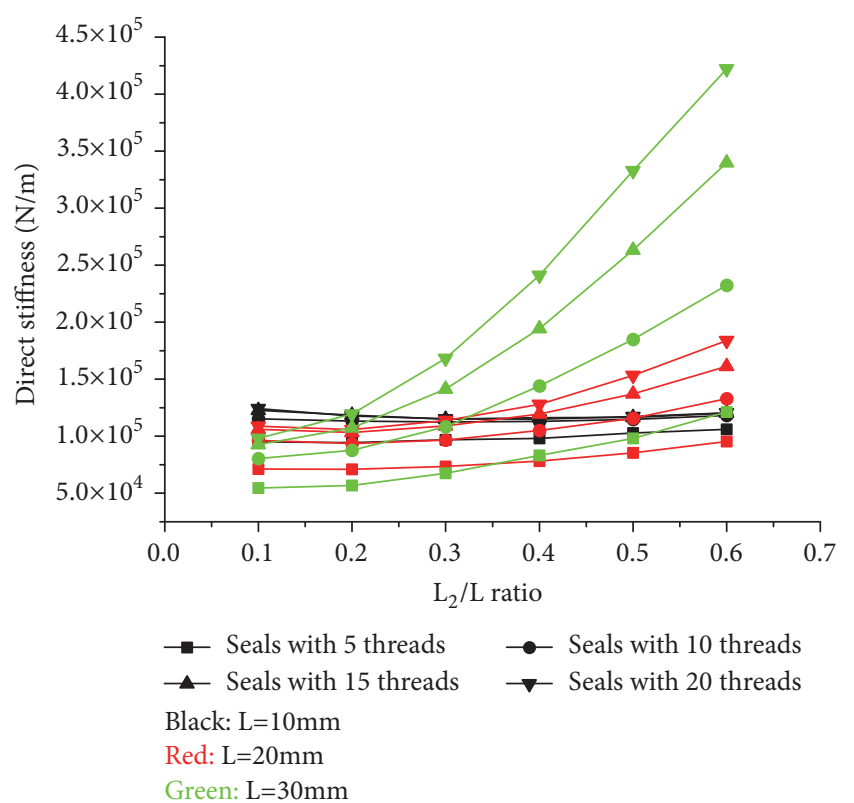

(a) Direct stiffness versus $\mathrm{L}_{2} / \mathrm{L}$ ratio

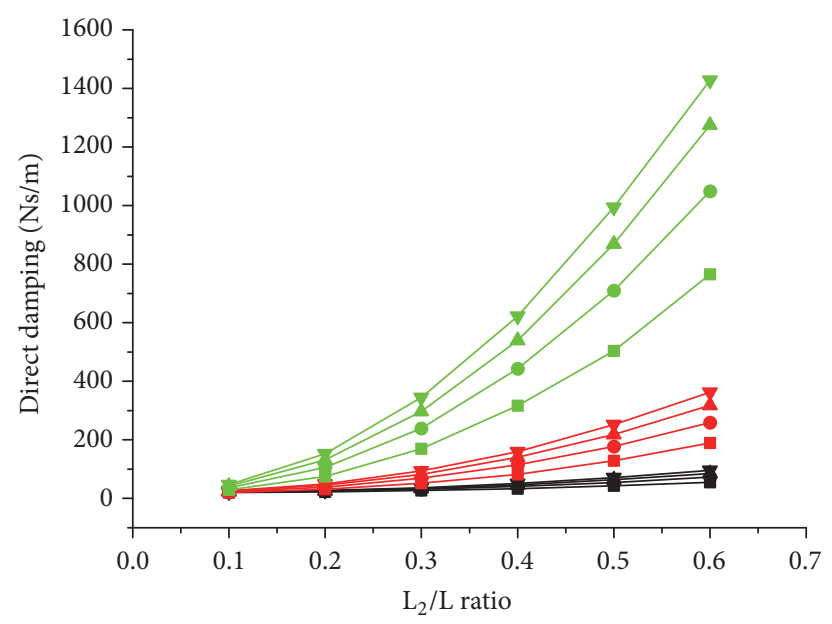

$\rightarrow$ Seals with 5 threads $\rightarrow$ Seals with 10 threads Black: $\mathrm{L}=10 \mathrm{~mm}$ Red: $\mathrm{L}=20 \mathrm{~mm}$ Green: $\mathrm{L}=30 \mathrm{~mm}$

(c) Direct damping versus $\mathrm{L}_{2} / \mathrm{L}$ ratio

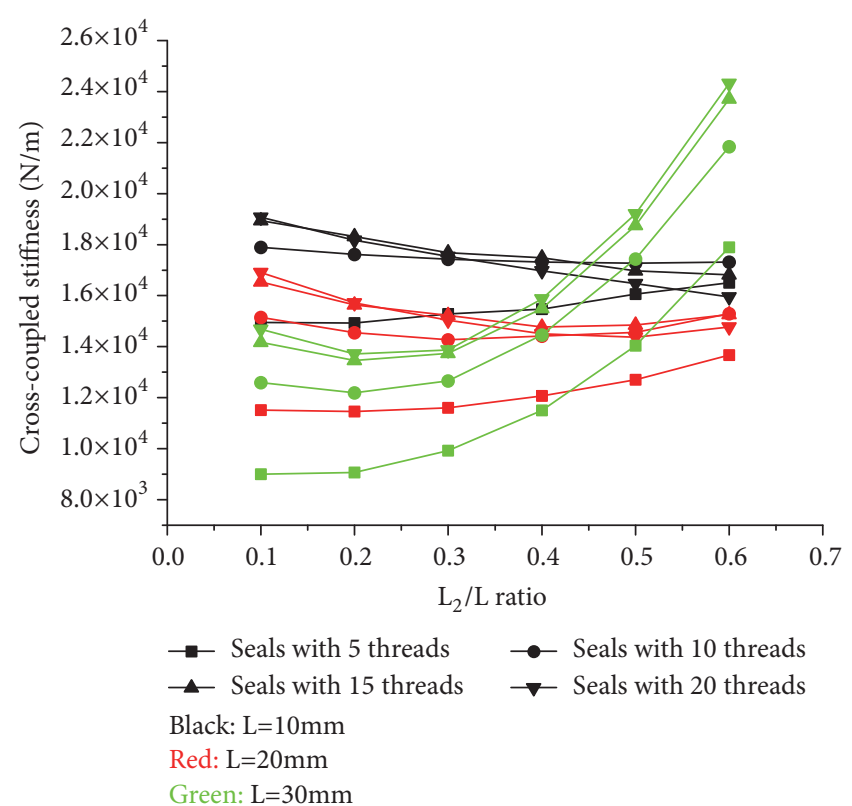

(b) Cross-coupled stiffness versus $\mathrm{L}_{2} / \mathrm{L}$ ratio

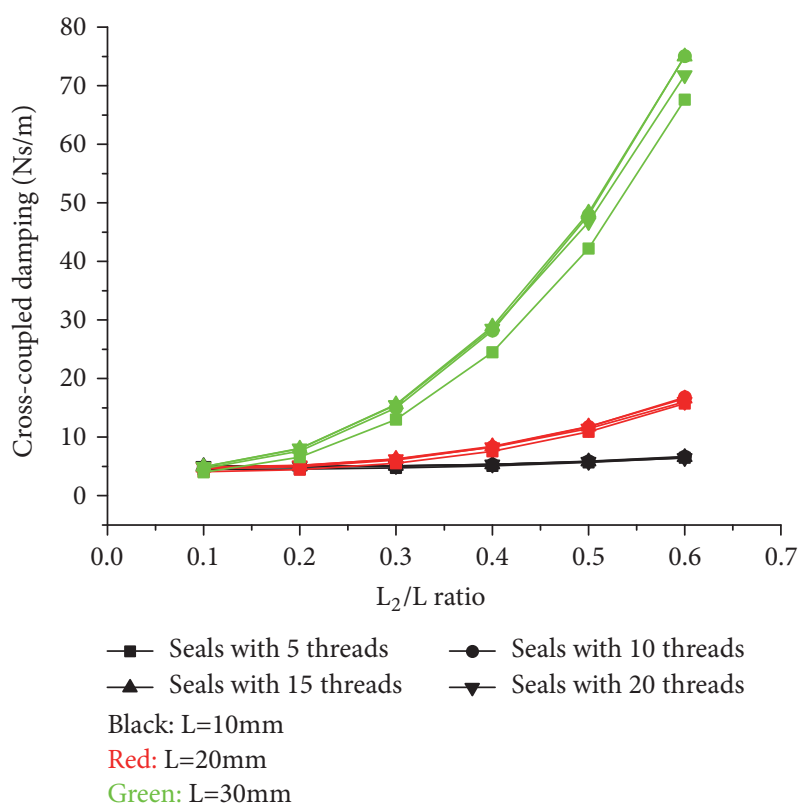

(d) Cross-coupled damping versus $\mathrm{L}_{2} / \mathrm{L}$ ratio

FIgURE 12: Dynamic characteristic changes versus $\mathrm{L}_{2} / \mathrm{L}$ ratio.

$P_{\mathrm{b} 2}$ : Boundary pressure at the outlet of middle plain part

$P_{\text {in }}$ : Inlet pressure of the whole seal

$P_{\text {out }}$ : Outlet pressure of the whole seal

$\bar{p}_{0}$ : Nondimensional zero-order axial velocity

$Q: \quad$ Leakage flow rate

$R: \quad$ Seal radius

$R_{\mathrm{ez} 0}$ : Zeroth-order Reynolds number in axial direction

$R_{\mathrm{e} \theta 0}$ : Zeroth-order Reynolds number in circumferential direction

T: $\quad$ Groove depth $u$ : Velocity

$\bar{u}_{z 0}$ : Nondimensional zero-order axial velocity

$\bar{u}_{\theta 0}$ : Nondimensional zero-order circumferential velocity

$V:$ Average axial fluid velocity

$z$ : Axial coordinate

\section{Greek Letters}

$\alpha$ : Spiral angle

$\lambda$ : Friction coefficient

$\mu$ : Dynamic viscosity 
$\xi$ : Pressure loss coefficient

$\tau$ : Tangential force

$\Omega$ : Whirling speed

$\varepsilon$ : Perturbation coefficient

$\rho$ : Fluid density

$\omega$ : Rotating speed

\section{Subscript}

0: $\quad$ Zeroth-order solutions

down: Downstream spiral part

in: Inlet pressure loss

out: $\quad$ Outlet pressure loss

plain: Middle plain part

pumping: Pressure differences induced by pumping effects

$\mathrm{r} \zeta$ : In $\zeta$-direction for rotors

$\mathrm{r} \eta$ : $\quad$ In $\eta$-direction for rotors

s $\eta: \quad$ In $\eta$-direction for stators

s $\zeta: \quad$ In $\zeta$-direction for stators

sp, -sp: $\quad$ Spiral part

up: $\quad$ Upstream spiral part

$\zeta: \quad \zeta$-Direction

$\eta: \quad \eta$-Direction

$\theta: \quad$ Circumferential direction.

\section{Data Availability}

The data used to support the findings of this study are available from the corresponding author upon request.

\section{Conflicts of Interest}

The authors declare no conflicts of interest.

\section{Acknowledgments}

This work was supported by the Joint Project from National Natural Science Foundation of China and Liaoning Province (Grant no. U1608258), Zhejiang Province Public Welfare Technology Research Project (Grant no. LGG18E060007), and Science Foundation of Zhejiang Sci-Tech University (ZSTU) (Grant no. 15022083-Y).

\section{References}

[1] A. G. Kostyuk, "Theoretical analysis of the aerodynamic forces in labyrinth glands of turbomachines," Thermal Engineering (English translation of Teploenergetika), vol. 19, no. 11, pp. 39-44, 1972.

[2] T. Iwatsubo, B. Yang, and R. Ibaraki, "Static and dynamic characteristics of parallel-grooved seals," in Proceedings of Rotordynamic Instability Problems in High Performance Turbomachinery, NASA CP-2443, pp. 99-127, Texas A \& M University, 1986.

[3] T. Iwatsubo, B. Yang, and R. Ibaraki, "Theoretical approach to obtaining dynamic characteristics of noncontacting spiralgrooved seals," in Proceedings of Rotordynamic Instability Problems in High Performance Turbomachinery, NASA CP-2443, pp. 155-188, Texas A \& M University, 1986.
[4] H. Iwatsubo, T. Nishino, and H. Ishimaru, "A study on dynamic characteristics of double spiral grooved seals," in Proceedings of Rotordynamic Instability Problems in High Performance Turbomachinery, NASA CP-3344, pp. 113-134, 1996.

[5] D. W. Childs and J. K. Scharrer, "An iwatsubo-based solution for labyrinth seals: Comparison to experimental results," Journal of Engineering for Gas Turbines and Power, vol. 108, no. 2, pp. 325331, 1986.

[6] R. Nordmann, F. J. Dietzen, W. Janson et al., Rotordynamic Coefficients And Leakage Flow of Parallel Grooved Seals And Smooth Seals, pp. 129-153, NASA. Lewis Research Center Rotordynamic Instability Problems in High-Performance Turbomachinery, 1986.

[7] C.-H. Kim and D. W. Childs, "Analysis for rotordynamic coefficients of helically-grooved turbulent annular seals," Journal of Tribology, vol. 109, no. 1, pp. 136-143, 1987.

[8] S. Florjancic, Annular Seals of High Energy Centrifugal Pumps: A New Theory And Full Scale Measurement of Rotordynamic Coefficients And Hydraulic Friction Factors, Swiss Federal Institute of Technology, Switzerland, 1990.

[9] O. R. Marquette and D. W. Childs, "An extended three-controlvolume theory for circumferentially-grooved liquid seals," Journal of Tribology, vol. 118, no. 2, pp. 276-285, 1996.

[10] M. Arghir and J. Frene, "Analysis of a test case for annular seal flows," Journal of Tribology, vol. 119, pp. 408-415, 1997.

[11] L. Zhai, G. Wu, X. Wei, D. Qin, and L. Wang, "Theoretical and experimental analysis for leakage rate and dynamic characteristics of herringbone-grooved liquid seals," Proceedings of the Institution of Mechanical Engineers, Part J: Journal of Engineering Tribology, vol. 229, no. 7, pp. 849-860, 2015.

[12] L. Zhai, Z. Zhenjie, C. Zhonghuang, and G. Jia, "Dynamic analysis of liquid annular seals with herringbone grooves on the rotor based on the perturbation method," Royal Society Open Science, vol. 5, no. 6, p. 180101, 2018.

[13] A. Ikemoto, T. Inoue, K. Sakamoto, and M. Uchiumi, "Nonlinear analysis of rotordynamic fluid forces in the annular plain seal by using extended perturbation analysis of the bulkflow theory (influence of whirling amplitude in the case with concentric circular whirl)," Journal of Tribology, vol. 140, pp. 041708, no. 4, 2018.

[14] S. A. Luis, T. Wu, H. Maeda et al., "A computational fluid dynamics modified bulk flow analysis for circumferentially shallow grooved liquid seals," Journal of Engineering for Gas Turbines and Power, vol. 140, no. 1, p. 012504, 2018.

[15] F. Cangioli, P. Pennacchi, G. Riboni et al., "Sensitivity analysis of the one-control volume bulk-flow model for a 14 teeth-onstator straight-through labyrinth seal," in Proceedings of the ASME Turbo Expo 2017: Turbomachinery Technical Conference and Exposition, pp. V07AT34A002-V07AT34A002, Charlotte, North Carolina, USA.

[16] K. Nagai, S. Kaneko, H. Taura, and Y. Watanabe, "Numerical and experimental analyses of static characteristics for liquid annular seals with helical grooves in seal stator," Journal of Tribology, vol. 140, pp. 032201, no. 3, 2018.

[17] P. Xia, Z. Liu, X. Yu, and J. Zhao, "A transient bulk flow model with circular whirl motion for rotordynamic coefficients of annular seals," Chinese Journal of Aeronautics, vol. 31, no. 5, pp. 1085-1094, 2018.

[18] L. Zhai, Z. Zhu, Z. Zhang, J. Guo, and B. Cui, “Theoretical solutions for dynamic characteristics of spiral-grooved liquid seals," Tribology Transactions, pp. 1-48, 2018. 
[19] H. Kanki and T. Kawakami, "Experimental study on the static and dynamic characteristics of screw grooved seals," Journal of Vibration and Acoustics, vol. 110, no. 3, pp. 326-331, 1988.

[20] T. Iwatsubo, B. C. Sheng, and M. Ono, "Experiment of static and dynamic characteristics of spiral grooved seals," in Proceedings of the Sixth Workshop on Rotordynamic Instability Problems in High-Performance Turbomachinery, pp. 223-233, 1990.

[21] D. W. Childs, "SSME seal test program: leakage tests for helically-grooved seals," NASA Progress Report, 1983, No. 833716 .

[22] D. W. Childs, S. A. Nolan, and J. J. Kilgore, "Test results for turbulent annular seals, using smooth rotors and helically grooved stators," Journal of Tribology, vol. 112, no. 2, pp. 254258, 1990.

[23] M. P. Proctor and I. R. Delgado, "Preliminary test results of a non-contacting finger seal on a herringbone-grooved rotor," NASA Technical Memorandum, 2008.

[24] S. H. Winoto, Z. Q. Hou, S. K. Ong, C. C. Rondonuwu, and Q. D. Zhang, "Effects of herringbone groove patterns on performance of vertical hydrodynamic journal bearings," Tribology Transactions, vol. 45, no. 3, pp. 318-323, 2002.

[25] Y. Qiu and M. M. Khonsari, "Investigation of tribological behaviors of annular rings with spiral groove," Tribology International, vol. 44, no. 12, pp. 1610-1619, 2011.

[26] J. H. Vohr and C. Y. Chow, "Theoretical analysis of spiralgrooved screw seal for turbulent operation," Journal of Lubrication Technology, vol. 91, no. 4, pp. 675-686, 1969.

[27] G. G. Hirs, "A systematic study of turbulent film flow," Journal of Lubrication Technology, vol. 96, no. 1, pp. 118-126, 1974.

[28] D. W. Childs, "Finite-length solutions for rotordynamic coefficients of turbulent annular seals," Journal of Lubrication Technology, vol. 105, no. 3, pp. 437-444, 1983. 

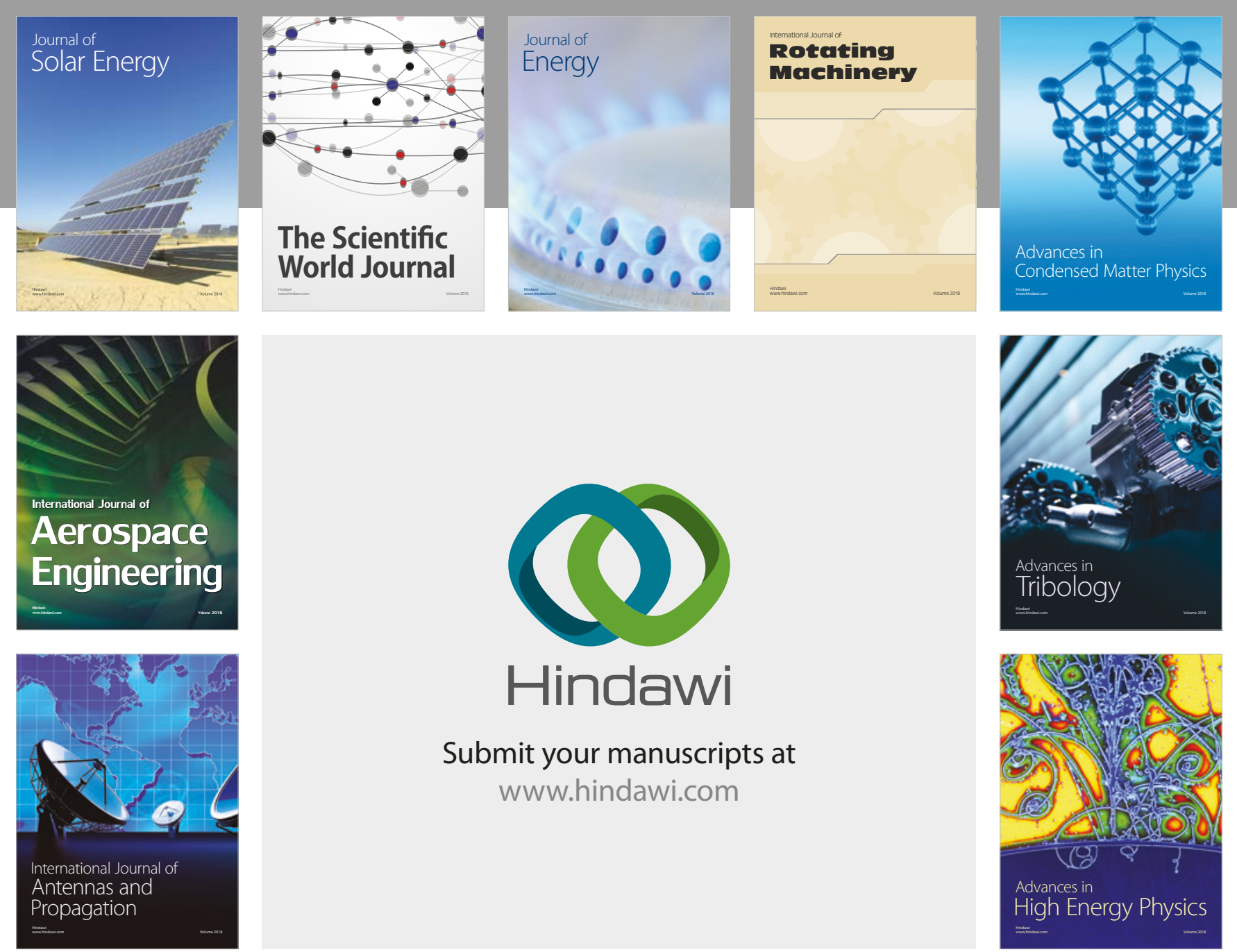

Submit your manuscripts at

www.hindawi.com
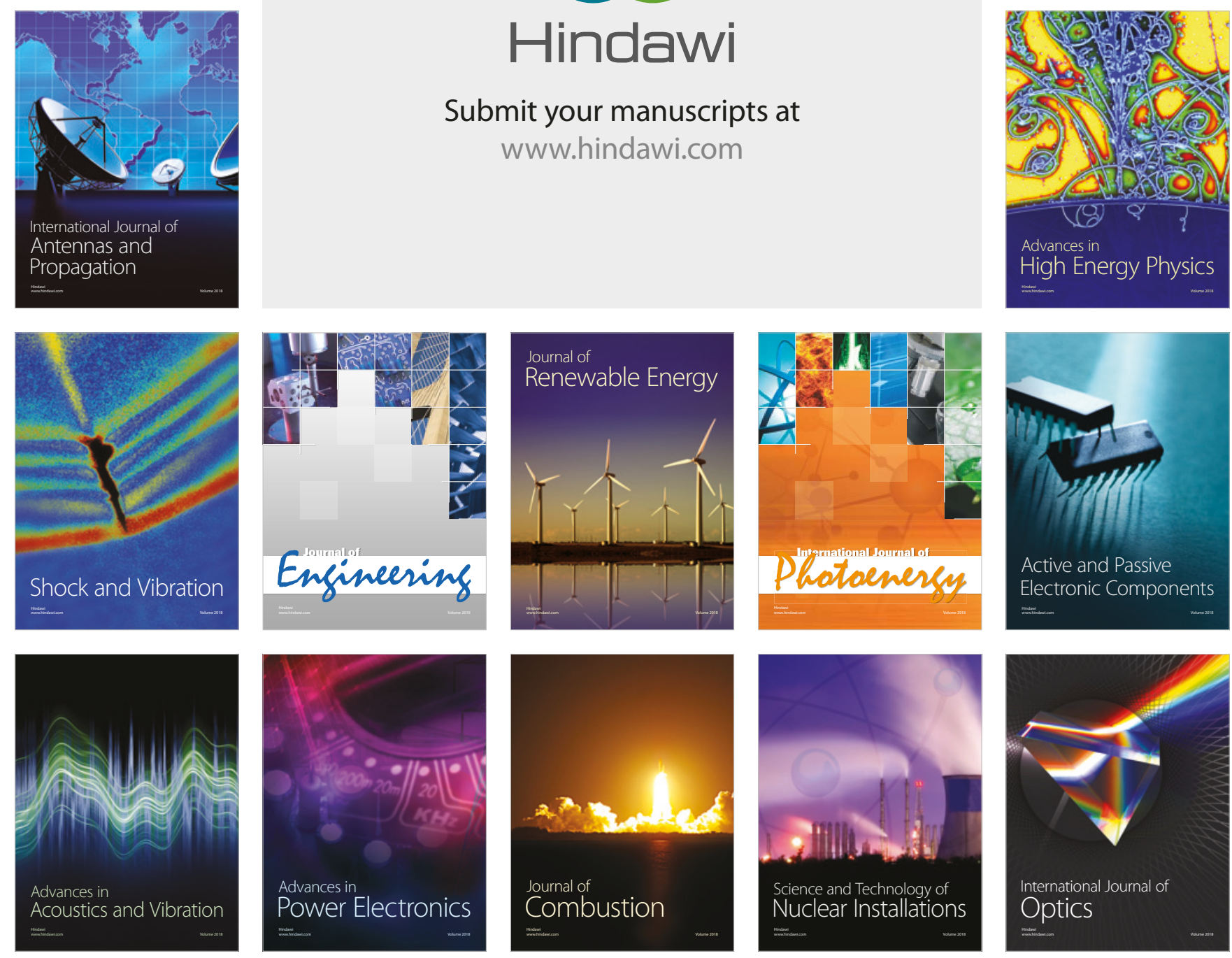